DOI: $10.24234 /$ wisdom.v15i2.361

Olena POLISHCHUK,

Iryna VITIUK,

Nataliia KOVTUN,

Volodymyr FED

\title{
MEMES AS THE PHENOMENON OF MODERN DIGITAL CULTURE
}

\begin{abstract}
The article analyzes an Internet meme as the newest information product of the society and a result of its intellectual and artistic practices. The analysis of the role of the Internet memes in the modern digital culture is made. Such methods as semiotic and hermeneutic analysis of the Internet memes are used in the research work. The authors seek to explore the reasons for the popularity of memes in the processes of symbolic production and exchange in contemporary society and the modern digital culture. We consider that Internet meme created by using and modifying artistic images is a new phenomenon in human public life and new type of communication. As a hypothesis, a distinctive feature of the Internet meme is the surprise and laughter it causes in the "man of the Internet". The main result of this article is the analysis the role of Internet memes in the newest information space and their specific features as a special information product of the modern digital culture. The authors draw attention to the popularity of Internet memes caused by an increase in information chaos in the modern symbolic production and exchange and a person's confusion when meeting a large number of information.
\end{abstract}

Keywords: Internet meme, digital culture, Web 2.0, Web 3.0, social media, intellectual practices, artistic practices, information product, communication.

Introduction

The newest information space is full of various entertaining information projects and products. For example, on TV these are talk shows and game shows, television films or series, etc. Popular cinema and cartoons, popular literature, video games and social media are also of great interest to contemporaries. In the last few years, they are increasingly joining a new information product which only strengthens the desire for games, entertainment, and communication on the Web in a person of the times of consumerism.
The second generation of the Internet was created due to Web 2.0 technologies (Tim O'Reilly and O'Reilly Media). There are Web Mash-up, Ajax, Google Suggest, Google Maps, Gmail, etc. Thus, the Internet offered various media services, aggregators, sites such as Quintura, Youtube, Pligg, del.icio.us, Digg.com, Netvibes, MySpace, Flickr, and other. There are Web objects, but individual consumers are subjects who want to communicate every day. This is a digital culture phenomenon in the newest society. Related services of Web 2.0 technologies created a new situation in the information realm 
of our society and led to new relationships between individual Internet consumers. The enormous popularity of social media has led to a new situation in the information space as well as relations between individual consumers. This is a cardinal shift in the relationship between individual consumers and the Internet as a system in the processes of symbolic production and exchange, for creative consumers became a new centre of symbolic value production; they can create and transfer their content on the Web. Thus, they need information exchange and cooperation between firms and users. Due to the ability to publish various messages on the Internet, consumers get in touch with different people, and some of them are known. Nevertheless, other people are unknown; this is a different type of communication (Berthon, Pitt, Plangger, \& Shapiro, 2012). Thus, it is a new type of communication because "digitalization of communication enhanced information and opinion sharing opportunities and provided a space for open and horizontal communication" (Hakobyan, 2020, p. 19). To our mind, the information sphere of modern society and its intellectual practices are being radically transformed.

The intensity of such changes will be further deepened by the development of Web 3.0 technology (Jason Calacanis and Netscape.com). Therefore, to keep up with this problem of modern social life, researchers must consider how the online environment affects contemporary society (van der Werff, Real, \& Lynn, 2018). It is important to note that the evolution of user interaction with modern web-technologies can lead to unexpected consequences in everyday human life, and not only in the performance of professional duties of each of us. Semantic Web can change not only the scope of information activities but also make significant changes in the creation of symbolic values and control their dissemination. The desire of people to communicate and interact with each other is the basis of social symbolic production and exchange. However, the great popularity of social networks has become a phenomenon of the information society.

Why did social networks become so popular among contemporaries? Blogosphere and forums, posting and chats, photos and videos from Instagram Posts, messaging, tweets, tags, forums, etc. exist because of the desire of people to communicate. Moreover, this type of communication is a new phenomenon in public life. In the information society, staying on Facebook, Twitter and Telegram is in great demand because of the ability to communicate with friends, and sometimes completely unknown people.

For example, many contemporaries, especially young people, are helped by Telegram videos or photos to get entertainment, distracted from monotony and life problems. After all, this cross-platform messenger since 2013, due to the exchange of media files of various formats and messages, fills free time. It helps to overcome boredom, entertains, introduces news, and makes it possible to meet something still unknown. Nevertheless, it also offers public statistics services and bots for commenting on posts and more. Such communication, as a form of social interaction, creates a temporary form of human integration and is perceived positively by many contemporaries. However, another important reason for its popularity, to our mind, is laughter or fun, which reduces stress from the monotony, challenges or difficulties of everyday life of contemporaries. As an example, an Internet meme or prank is entertainment.

Therefore, it is essential to research how and what the online environment affects people's daily lives. There are, first of all, privacy issues 
when disclosing personal information on the Internet (Bente, Rüggenberg, Krämer, \& Eschenburg, 2008); increased social presence thanks to network avatars (Bansal, Zahedi, \& Gefen, 2016); the role of interpersonal trust in networking (van der Werff, Real, \& Lynn, 2018). The phenomenon of modern digital culture is the popularity of memes. The Internet meme sets the task for modern scientists to analyze Internet signs as elements of modern digital culture, which is rapidly forming in recent years (Cannizzaro, 2016). Memes are a fairly new phenomenon in the symbolic production and exchange of modern society, which has not yet attracted the attention of scientists.

We seek to explore the reasons for the popularity of memes in modern digital culture as the purpose of this study. We also want to consider its most characteristic features as an individual information product in symbolic production. The object of our research is a specific group of Internet memes, namely: memes created using and modifying artistic images.

\section{Internet Meme in the Newest Information Space and Its Specific Features}

It should be noted that a meme exists in the form of a specific media object, such as a photo or video. This object usually exists with a caption, less often a phrase or some slogan, a specific optical effect, etc. That is, it acts in the symbolic production of modern society as a specific information product, which arose due to the use of video, photo, reproductions of a picture, frame from a film or an animated film, soundtrack, etc.

Such an object had some kind of prototype in modern mass culture. Less commonly, its occurrence is associated with the use of cultural heritage items of some epoch, people or particu- lar country. Furthermore, its occurrence is associated with the transformation of the prototype, its transcoding in terms of meaning. To our mind, this gives reason to consider such an information product as a simulacrum in modern culture. It also is the result of simulations in the symbolic production and exchange of contemporary society. Thus, we strive to explore the connection between meme, simulacra and simulations using a Web resource, such as social networks, blogs, messengers, etc.

According to Carlos Castaño, finding a concrete definition of a meme is difficult because it is necessary to study this phenomenon in cultural analysis and scholarly contexts. To his mind, "a broader concept of meme gives more stability to the construction of the concept of "Internet meme". As a matter of fact, the present research assesses five theorists that have studied the concept of a meme and are, simultaneously, up to date in the research field of meme studies: Dan Sperber, Susan Blackmore, Daniel Dennet, Mogens Olesen and Richard Dawkins". This researcher claims that a meme should be considered a specific informational "unit of transmission that can replicate itself utilizing imitation, and that possesses three characteristics that make it successful: longevity, fecundity, and copyfidelity" (Castaño, 2013, p. 85). Thus, what are Internet memes? We want to point out that they are a particular kind of memes and the phenomenon of digital culture. In other words, "they perfectly fit in the epidemiologic theory of memes, with certain characteristics that are only proper of its own kind, allowing the emergence of new patterns of interchange, exchange and reproduction. Their themes can go from pure silliness to important social changes and the social environment, while the places, it strews, take an influential role in their development, pervasion, and 
decadence" (Castaño, 2013, p. 103). Therefore, the most crucial feature of such memes is the speed of distribution and the great attention of the public to them, and the public of different planes in the social structure of the newest society (education, age, profession, etc.).

Another specific feature of the Internet meme, as an information product, is that it exists in the form of a symbol(s) or image, an idea recorded on a specific electronic medium. It has a visual form or an integrated, visual and audio presentation form. This is an ephemeral object that exists thanks to Web technologies and Internet recourse.

The story of the Miss Piggy meme, popular in the English-speaking environment, gives an idea of how the Internet meme exists. Anyone can now have fun with funny pictures about Miss Piggy On several Internet resources. You can also have fun, looking at the various and numerous memes about Kermit.

Long ago admirers of the Anglo-American comedy show The Muppet Show, created by Jim Henson back in the 70s of the last century, became adults. This television program featuring puppet actors was popular not only among children but also among adults. The first appearance of such puppet actors in the information space took place back in 1974 in the program The Muppets Valentine Show, in which the famous actress Mia Farrow took part. (Her participation ensured public interest in this type of media product). A year later, the successful television project was continued thanks to the Muppet Show: Sex and Violence. The glamorous Miss
Piggy and her friend, the frog Kermit, have become popular characters thanks to the capabilities of TV and its huge significance in everyday life of contemporaries.

However, the cinema also contributed to the increasing popularity of these media objects. The characters of the show gained even more popularity thanks to such films as The Muppet Movie (1979), The Great Muppet Caper (1981), Muppets Take Manhattan (1984), The Muppet Christmas Carol (1992), Muppet Treasure Island (1996), Muppets from Space (1999). The entertainment industry has offered the animated series Muppet Babies so that the children's audience will not be bored. The production of symbolic values can generate significant capital. Therefore, popular media characters continued their lives in the 21 st century; one by one the films went into the information space: It's a very merry Muppet Christmas movie (2002), Kermit's Swamp Years (2002), The Muppets' Wizard of Oz (2005), The Muppets (2011), Muppets Most Wanted (2014).

The appearance of memes about Miss Piggy or Kermit is a continuation of symbolic values circulation in modern society, but not only the possibilities of television and cinema are used here. These memes are products of Internet technology. Their popularity is provided by Internet resources and social networks.

Everyone who has access to them can watch Kermit \& Miss Piggy Memes as a collection of memes by Lucia Herrera (provided by electronic resource https://www.pinterest.com/luzylu84/kermit-miss-piggy-memes/). 


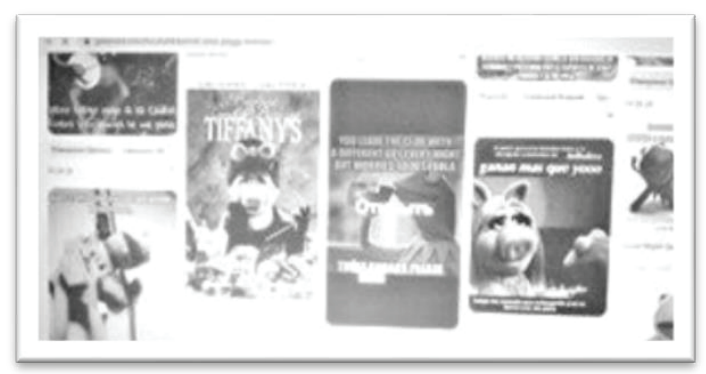

Illustration 1.

If desired, every adult or child can watch How's Your Body Image Today? Wait, Don't Answer That on Web resource: utterlyinexperienced.blogspot.com (electronic resource https:// www.pinterest.com/pin/527906387550107252/). This resource even has its own slogan: Love miss piggy!! She knows what she's talkin about! (We saved the spelling of the original).

On Facebook, there are also memes about puppet dolls. As an example, we will point out Kermit \& Miss Piggy Memes (electronic source @kermitmisspiggymemes; https://www.facebook.com/kermitmisspiggymemes/). This page was created by an anonymous author on February 8 , 2018. (It is interesting that 2,362 people liked the statistics for this time, and 2,561 people supported it financially, as of June 21, 2020). A significantly larger number of followers have another

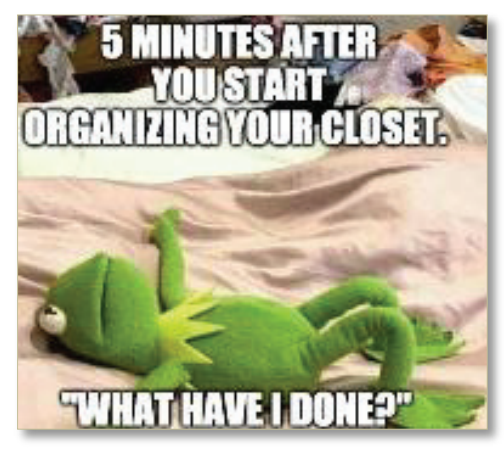

Illustration 3.

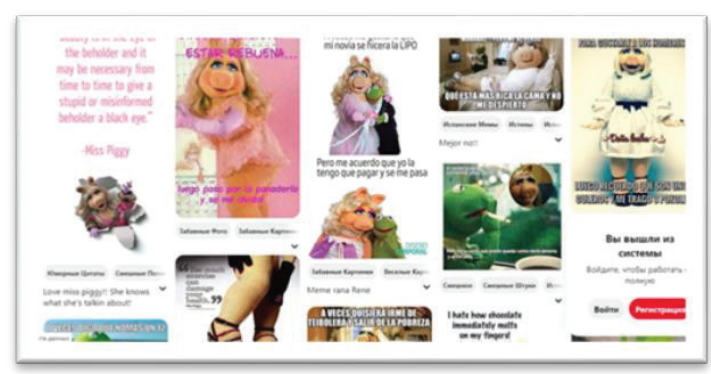

Illustration 2. resource, page created on December 21, 2010. This is Kermit the Frog (electronic resource @MuppetsKermit; http://facebook.com/MuppetsKermit). This Facebook page has more than 2 million subscribers (as of 06/21/2020). As you can see, memes about Kermit are very popular. And creating them is profitable, as well as replicating thanks to Internet resources or distributing them on social networks. Miss Piggy Memes also bring significant revenue to their creators, as they are able to entertain contemporaries. As an example, we point to a Facebook page such as Miss Pigg. (It was created on December 21, 2010; access mode: @MuppetsMissPiggy and http://facebook.com/MuppetsMissPiggy). This page also has more than a million subscribers; it is monitarized (as of 06/21/2020).

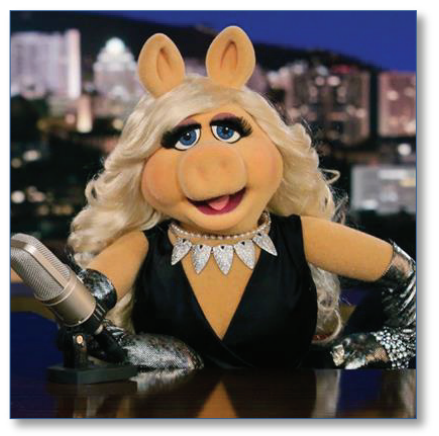

Illustration 4.

for creating a meme in general and an Internet meme in particular. Nevertheless, the condition for its appearance is a combination of visual imtures; an idea or even a sign can serve as a basis 
age, including artistic one, with an unexpected element. They most often have a different visual image, the combination of which will be provided by Photoshop or another graphic editor.

For example, this is unusual in meaning inscription or slogan that accompanies a photo; original and unexpected text fragment, placed on reproductions of a famous work of art; a pattern that distorts a prototype pattern, etc. Much less often, the soundtrack will accompany the photo as an unexpected phrase, oxymoron, etc.

An attempt to distinguish between types of memes is interesting: firstly, "mem-gene", which is a specific "unit of cultural transmission or a unit of imitation" (Castaño, 2013, p. 84); and, secondly, the "meme virus". The latter arises due to the significant interest of various people on the Web and the rapid spread by the Internet (Castaño, 2013, p. 85-86). Therefore, it can be compared in speed and unexpectedness to "computer viruses" (Castaño, 2013, p. 88). This is a characteristic feature of the Internet meme: it is the socalled viral distribution that is significant popularity due to the great interest of ordinary people and its rapid spread in various ways due to Web technologies.

Author of memes can be different people, including professionals in the field of modern visual technology, when it comes to promoting a media product: advertisers, designers, photographers etc. But in principle, anyone who is familiar with computers, the Internet, and Photoshop can create a meme. It is essential that such a person has a good sense of humour and is endowed with creative thinking. He also has, in our opinion, to be able to create a visual image, intuitively feeling the absurdity of combining all its elements. It is the absurdity that the viewer faces in the meme that causes laughter.

A distinctive feature of the Internet meme is the surprise and laughter it causes in the "man of the Internet". Laughter can have different causes. That is, depending on the goal pursued by the meme's author, laughter will be different: irony, humour, sarcasm, and others. Quite often, laughter is caused even by satire, which is resorted to by the author of such media product. Laughter occurs when another person perceives the visual or audio-visual image created by him with an understanding of the semantic load of this image, similar to the thoughts and feelings of the person who created the Internet meme.

\section{Internet Meme as a Result of Intellectual} and Artistic Practice of Contemporaries

We consider the Internet meme is recognized by a consumer as a valuable product of the newest symbolic production and exchange in the society as users know "their data can be used for commercial purposes, and still they continue active, communicative practices, as social media provides them with the best platform for the Castellsian mass self-communication". Furthermore, this very reason stimulates their activity, the "hierarchic and competitive structure of social media also triggers the users to seek for more popularity and to be more active" (Hakobyan, 2020, p. 22). It is important to emphasize this is a visual product, rarely a product combining visual and audio information. Therefore, we want to take a more in-depth look at the reasons for the popularity of such digital objects among contemporaries. Why are Internet memes so popular now? There seem to be many reasons. It is necessary to investigate the connection between the popularity of memes and the use of laughter (due to irony, cartoon, parody, grotesque), as one of the main tasks of this study.

The newest days of humanity are a new pe- 
riod of its history; we have a globalization process, information technology, and the other way of social development (Castells, 1999). Reflecting on the prospects for the development of society and the future of mankind as a whole, we can assert the beginning of a new period of their existence as the Internet Galaxy (Castells, 2001).

In April 2013 "Industrie 4.0 Working Group" pointed the perspectives of the society transformation as follows: "The future, businesses will establish global networks that incorporate their machinery, warehousing systems and production facilities in the shape of Cyber-Physical Systems (CPS). In the manufacturing environment, these Cyber-Physical Systems comprise smart machines, storage systems and production facilities capable of autonomously exchanging information, triggering actions and controlling each other independently. This facilitates fundamental improvements to the industrial processes involved in manufacturing, engineering, material usage and supply chain and life cycle management. The Smart Factories, already beginning to appear, employ a completely new approach to production. Smart products are uniquely identifiable, may be located at all times and know their history, current status and alternative routes to achieving their target state. The embedded manufacturing systems are vertically networked with business processes within factories and enterprises and horizontally connected to dispersed value networks that can be managed in real-time - from the moment an order is placed right through to outbound logistics. Besides, they both enable and require end-to-end engineering across the entire value chain" (Kagermann, Lukas, \& Wahlster, 2011, p. 5). Discussing the topic on Industrie 4.0 Mario Hermann, Tobias Pentek and Boris Otto consider that this "industrial revolution has been preceded by three other industrial revolutions in the history of mankind. The first industrial revolution was the introduction of mechanical production facilities starting in the second half of the $18^{\text {th }}$ century and being intensified throughout the entire $19^{\text {th }}$ century. From the 1870 s on, electrification and the division of labour (i.e. Taylorism) led to the second industrial revolution. The third industrial revolution, also called "the digital revolution", set in around the 1970s, when advanced electronics and information technology developed further the automation of production processes" (Hermann, Pentek, \& Otto, 2015, pp. 4-5). They have pointed to such social design principles for its implementation of the newest industrial revolution as 1) interoperability, 2) virtualization, 3) decentrelization, 4) real-time capability, 5) service orientateon, and 6) modularity. According to Michela Piccarozzi, Barbara Aquilani and Corrado Gatti (2018), the fourth industrial revolution transforms our society in the society of the Internet of things. It makes radical changes in the business model and strategy implementation of daily life towards sustainable development of the society.

First of all, the risks and situations of uncertainty caused by the transition of modern society to Industry 4, create tension and discomfort in social relations. It concerns not only the countries of Central and Eastern Europe, which in the recent past have faced manifestations of totalitarianism but now have significant economic problems due to a change in socio-political guidelines and attempts to modernize production quickly. Social tension has been recorded recently in other parts of Europe and the world as a whole. For example, these are civil protests in Venezuela that began in 2014. We will also point out civilian actions in Iran at the end of 2019 caused by the "gas crisis", protests caused by the crash of a PS 752 Tehran-Kiev flight in the winter of 2020, 
when citizens of 7 countries died and others. Protests against the installation of G5 cell towers took place in many regions of "Old Europe". We can also include migration protests in Greece in 2020 into a chain of similar events. Such situations are evidence of attempts to find effective ways to overcome social problems that are not solved by institutional mechanisms approved in society. Such cases of social instability are now increasingly becoming traits of pessimism in assessing the future and are becoming a characteristic sign of discomfort in the inner world of many contemporaries, their insecurity in the positive changes in everyday life today and in the future. Therefore, the search for entertainment on the Internet seems to be a logical link in the changes in the symbolic values of society and the individual. Memes make it possible to escape at least for a while into the "world of positive illusions", bringing pleasure.

Another important reason, in our opinion, is the process of urbanization. Residents of cities, especially megacities, are often forced to face an excess of visual irritants both in the workplace and in the organization of leisure and everyday life. In addition, traditional values such as the institution of the family, religious faith and the church, the national-cultural tradition, are no longer always effective social tools to reduce stress in the lives of contemporaries. Then Internet resources and social networks become clusters of social stability created due to symbolic production and exchange in modern society. Turning to Internet memes, in this case, is a way to reduce the internal discomfort that occurs in the daily lives of many cities, especially megacities, residents.

We believe that not only empathy takes place in acts of intentional social communication. When broadcasting a message from the au- thor of the meme to the consumers of the meme, ideas, meanings, intentions, etc. are transmitted. In other words, we are talking about an original form of intellectual practice of our time, acquaintance with the products of which does not require much time.

Here is a "multi-vector game" with the meanings of the message. We believe that it is always important for the author of memes to share information with other people, their intellectual and even emotional states. Nevertheless, it is unusual that consumers of memes are not known to their authors; it is an anonymous form of communication. Perhaps this also serves as an incentive for the distribution of memes on Internet resources and social networks, and not just a desire to earn from viewing such information products.

It is more difficult to explain the reasons of the permanent demand for such an information product in modern society, for it constantly becomes the "viral infection" for a large number of people. We believe that users of memes enjoy not only the intellectual game proposed by meme developers in this form of anonymous communication. Internet memes are, besides, the products of a particular artistic practice in times of digitalization. The meme consumer enjoys contemplating colour, shape, background, scale, proportions, rhythm, symmetry, asymmetry, etc. in the proposed video or digital photo. In this way, he, firstly, regulates the deficit of positive emotions in his own life.

Secondly, a person enjoys irony, humour, sarcasm, and sometimes satire, as varieties of the comic contained in the meme. Contemporaries lack positive emotions, and therefore laughter becomes utterly important to them. In our opinion, it is the meeting of users with comic situations that ensures the popularity of memes. The expectation of laughter and emotional release 
stimulate the search for such information products for contemporaries.

As an example, there is the work of an anonymous author with the nickname Klod Mande. He posts his works on Instagram, creating them as digital photo collages (Source: Photoshopping of an anonymous master use social network users; June 25, 2020 21:26. Electronic resource: https://internetua.com/fotojaby-anonimnogo-mastera-veselyat-polzovatelei-socsetei). He uses, as source material, frames from popular in the past Hollywood and Soviet films. Humor arising from an unexpected combination of different characters is one more peculiarity of his work. In this way, an unusual context of an information product is created by a talented illustrator, the transformation of the original artistic images creates a "fleur of meanings", and each user in this game enjoys an intellectual game with them. His collages have component integrity due to good composition and exciting placement of all elements. This is a vivid example of the digital work of an anonymous artist and the reasons for popularity. Using thematic photos, in this case, frames of famous feature films, an anonymous author creates a selection of caricature pictures.

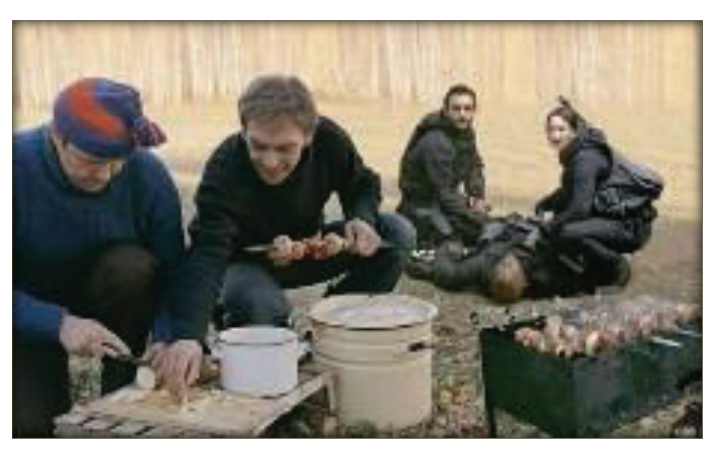

Illustration 5.

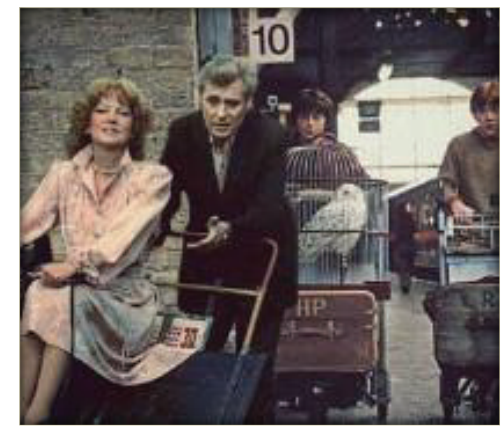

Illustration 6.
However, this is also an example of a new type of artistic practice in modern society. Photoshopping is a type of photomontage as creative processing by a member of the Internet community (blog, forum, etc.) of an image through the use of graphic editors such as Adobe Photoshop, Corel PHOTO-PAINT, Microsoft Paint and GIMP. Such content entertains users and is therefore popular.

Apparently, we are talking about the development of visual communication of society and its new elements. It depends on specific ways of visually capturing information, and the first map can be considered its beginning (Friendly \& Denis, 2005). Technological innovations, associated with the development of computer technol- ogy and the creation of new tools for graphic editing of information, have created a new stage in the development of visual communications (Labuz, 1991). As Christopher R. Harris and Paul M. Lester consider, journalism in visual media includes the work on a documentary, photography, graphic design and knowledge in ethics field; they are a kea of the successful visual communication and career (Harris \& Lester, 2002).

However, we want to point out that the anonymous authors of information products on social networks in particular and the Internet resource, in general, are not always an example of good faith. According to Adam Perer, the design to visualizing of the social networks is a mode to reduce the chaos of them and a way to the crea- 
tion of fascinating insights (Perer, 2010, pp. 157158).

In addition, we suggest that the interest in Internet memes can be caused by frequent meetings of modern people with advertising images. It must be pointed out that collages were often used and are now used in advertising (Vries, 1968). In addition, often, memes are a specific media product in advertising practice. As an example, we indicate the following. Miss Piggy Memes are closely associated with many advertising campaigns; advertising of clothes, drinks, etc. For example, in 2014, this image was actively used in English-speaking countries when advertising Lipton tea (see: TV Spot - Lipton Tea Lipton Helps Kermit - Be More Tea; 03/03/2014. Source: https://www.youtube.com /

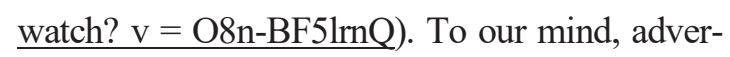
tising encourages people to control emotional and sensory states outside the realm of art. Advertising images entertain and therefore alleviate the stress of everyday life problems. Popular Internet memes also have this property.

\section{Conclusions}

As the conclusions of our analysis of Internet memes main features, as well as the reasons for their great popularity among contemporaries, we indicate the following.

- Internet memes are special media objects in the modern information space of society, as they have recently become significant agents of influence. One of the basic features of an Internet meme is its ability to create many copies (ideological or figurative) as an imitation.

- We draw attention to the fact that the mass enthusiasm for Internet meme is caused, as one of the reasons, by an increase in infor- mation chaos and, therefore, a person's confusion when meeting a large number of information pieces flows in modern symbolic production and exchange. Network structures in modern social communication have become an essential element of it, and the content they contain is very different in quality.

- Memes entertain people and therefore mitigate their stress arising from the problems of everyday life, uncertainty, risks, conflicts, etc.

- We draw attention to the fact that the ability determines the popularity of memes as media objects for a person to control their emotional and sensory states on their own. This happens outside the scope of traditional artistic practices, contemporary art, etc. The ability of Internet memes to surprise and laugh makes them attractive to contemporaries, and also makes them a new element of visual culture.

\section{REFERENCES}

Bansal, G., Zahedi, F. M., \& Gefen, D. (2016). Do Context and Personality Matter? Trust and Privacy Concerns in Disclosing Private Information Online. Information and Management, 53(1), 1-21. doi.org/10.1016/j.im.2015.08.001

Bente, G., Rüggenberg, S., Krämer, N. C., \& Eschenburg, F. (2008). Avatar-Mediated Networking: Increasing Social Presence and Interpersonal Trust in NetBased Collaborations. Human Communication Research, 34(2), 287-318. doi/10.1111/j.1468-2958.2008.00322.x

Berthon, P. R., Pitt, L. F., Plangger, K., \& Shapiro, D. (2012). Marketing Meets Web 
2.0, Social Media, and Creative Consumers: Implications for International Marketing Strategy. Business Horizons, 55(3), 261-271.

doi:10.1016/j.bushor.2012.01.007

Cannizzaro, S. (2016). Internet Memes as Internetsigns: A Semiotic View of Digitalculture. Sign Systems Studies, 44(4), 562-586.

doi:10.12697/SSS.2016.44.4.05

Castaño, D., C. M. (2013). Defining and Characterizing the Concept of Internet Meme. Revista CES Psicologia, 6(2), 82-104.

Castells, M. (1999). Information Technology, Globalization and Social Development. United Nations Research Institute for Social Development.

Castells, M. (2001). The Internet Galaxy. Reflections on the Internet, Business, and Society. Oxford University Press.

Friendly, M., \& Denis, D. (2005). Milestones in the History of Thematic Cartography, Statistical Graphics and Data Visualization. New York: Springer.

Hakobyan, A. (2020). Theory Digitalization of Communication and the Spiral of Silence. Wisdom, 1(14), 19-27. doi:10.24234/wisdom.v14i1.312

Harris, C. R., \& Lester, P. M. (2002). Visual Journalism: A Guide for New Media Professionals. Boston: Allyn and Bacon.

Hermann, M, Pentek, T., \& Otto, B. (2015). Design Principles for Industrie 4.0. Scenarios: A Literature Review, Working Pa- per. Technische Universität Dortmund.

Kagermann, H., Lukas, W.-D., \& Wahlster, W. (2011, April). Industrie 4.0: Mit dem Internet der Dinge auf dem Weg zur 4. Industriellen Revolution. VDI nachrichten -1, 13 .

Kagermann, H., Wahlster, W., \& Helbig, J. (2013). Securing the Future of German Manufacturing Industry: Recommendations for Implementing the Strategic Initiative Industrie 4.0: Final report of the Industrie 4.0 Working Group. National Academy and Engineering.

Labuz, R. (1991). Contemporary Graphic Design. New York: Van Nostrand Reinhold.

Perer, A. (2010). Visualizing Social Networks. In J. Steele \& N. Iliinsky (Eds), Beautiful Visualization: Looking at Data through the Eyes of Experts (pp. 157-160). Sebastopol, CA: O'Reilly Media.

Piccarozzi, M., Aquilani, B., \& Gatti, C. (2018). Industry 4.0 in Management Studies: A Systematic Literature Review. Sustainability, 10(10), 3821, 2-24. doi.org/10.3390/su10103821

van der Werff, L., Real, C., \& Lynn, T. (2018). Individual Trust and the Internet. In R. Searle, A. Nienaber, \& S. Sitkin (Eds.), Trust (pp. 3-6). Oxford, UK: Routledge.

Vries, L. de. (1968). Victorian Advertisements. London: William Clowes and Sons Limited. 